\title{
ENGLISH LANGUAGE TEACHER EDUCATION: NOTES ON THE PAST AND FUTURE
}

\author{
GUY COOK \\ Department of Education and Professional Studies \\ King's College London
}

\begin{abstract}
:
The first part of this paper considers approaches to teacher education for EFL developed during the 1960s-1990s, drawing upon two sources: the taxonomy of three approaches proposed by Wallace (1991) and personal reminiscence. It discusses each of Wallace's approaches in turn: craft, 'applied science', and reflective practice.The second part considers whether these approaches are adequate models for teacher education now. I suggest that while they are still relevant, they are also too inward looking for contemporary needs. They need to be supplemented with a more outward looking approach, in which teachers are prepared to engage with four aspects of the contemporary context: new communication technologies, the new global linguistic landscape, the relationship between English and learners' own languages, and the rival political views of English language learning as promoting either a global neoliberal agenda or a global civil society.
\end{abstract}

Keywords: English Language Teaching, teacher education, new media, L1 use in language learning, civil society.

The first years of the 21st century have seen immense changes in the world's linguistic landscape. English teacher education, however, has not altered in tandem. It remains locked into past models, rather than trying to achieve contemporary relevance. The theoretical and practical approaches to language teaching which grew so exponentially from the 1960s through to the 1990s, together with the applied linguistics theories and descriptions which underpinned them, are a rich resource, but should not become a weight around our necks. We need to keep those elements which are still relevant in our altered age, but add new dimensions of our own.

\section{The past}

I begin historically, before discussing the present and the future. To talk about the past, I will draw upon two sources. The first is an influential taxonomy of 
three models of teaching proposed over twenty years ago by Mike Wallace (1991): "craft", "applied science", and "reflective practice". The second source is a series of snapshots from my own personal memories and impressions. For I am myself a creature of the past, having been involved in language learning - as a learner, a teacher, then a teacher educator-for 50 years. It is not that my experience is in any way special-it is one shared by many others. Any individual's experiences are part of a bigger picture, and mine are no exception. It is only retrospectively that we realise that what seemed to be our special personal experiences and emotions are part of larger trends, reflecting moods of the times, and moments in history. This is as true in language teaching and language teacher education, as in the world more generally.

\section{Tradition}

Let us begin with the 1950s and 1960s and a "traditional" notion of language teaching, which existed largely outside any theoretical framework. We might characterise it as based on the belief that the single most important quality of a good teacher is academic knowledge of the subject matter (Clark 1987: 5-14). This is my first snapshot. I am sitting at my desk learning French in 1962 at the age of ten. Our teacher had one qualification - his own confident knowledge of French grammar and vocabulary. His pedagogic technique - such as it wasconsisted solely of setting translation exercises, then pacing up and down between the rows of desks with an unlit pipe in his mouth, before collecting in the work and correcting every error in red pen. Everything happened in enforced silence - there was no talking in a language lesson! And there was no colloquial language either. When after three years study of French I went to Belgium on an exchange, I had to write home to my sister to ask if she knew the meaning of "ça va"!

\section{Craft}

But at thevery same time, a new approach to language teaching was taking hold in the world of EFL. Like many movements of the 1960s it appeared to be dynamic, iconoclastic, and liberating: a radical departure from authoritarian traditional teaching. Yet in retrospect, just as with many other currents of the 60 s, some elements of it appear now to be just the opposite: retrogressive and chauvinistic. (What seemed to be sexy and sexually liberating in 60 s films for example can now seem very sexist.) Unlike my pipe-smoking schoolmaster, the teachers of this new dispensation were not required to master their subject matter - the grammar and lexis of English - because as young native-speakers, they were believed to know it already. This assumption drew upon, though it was never authorised by, the ascendant Chomskyan linguistics of the time, which 
equated a language with native-speaker knowledge (Chomsky 1965:3-5). (Chomsky himself, however, has always vehemently denied any relevance of linguistics for language teaching or teacher education, saying that the ideas of applied linguistics and psychology are "often ... totally crazy", and have caused "a good deal of harm by pretending to have answers ... and telling teachers ... how they should behave" (Chomsky 1988: 180-182).

Given the belief that this new wave of native-speaker teachers already knew their subject matter, the attention in EFL teacher training of this period focused almost exclusively upon methods and techniques (Anthony 1963) that would oust the traditional approach, in much the same spirit as the contemporaneous mop hairstyles of the Beatles ousted the short-back-and-sides haircuts of the 50s. Equipped only with native-speaker intuitions and hastily imbibed classroom techniques, imparted in very short training courses, these native-speaker teachers set off throughout the world like troubadours, convinced that language-learning success for their students meant emulation of their own automated knowledge and use of English. This faith in native-speaker knowledge was not new-it dates back at least to the 1870s (Cook 2010:3-26, Howatt 2004: 157-209) — but in the atmosphere of the 60s it took on a new lease of life.

The change and the mood of the times is caught well in the snappy enthusing dynamic style of a pioneer, John Haycraft, the founder of International House.

\footnotetext{
"Our teachers needed to know how to use visual aids, build their lesson on whatever English had already been taught, relate new vocabulary to objects in the classroom, or brought in from outside. Trainees had to learn how to mime and communicate dramatically, and use the kind of situational background which was relevant to our students language needs." (Haycraft 1998)
}

Language teaching was to be immediate, confident, a-theoretical, handson-with none of the heavy slow progress of traditional language teaching. This was a Brave New World of visual aids, mimes, and role play by means of which enthusiastic young teachers were to accomplish the extraordinary feat of teaching people with whom they had no language in common. The focus would be on idiomatic immediate use in face-to-face communication. The appropriate preparation, run by various bodies, were short three or four week training courses - one descendant of which is today's CELTA (Certificate in Teaching English to Speakers of Other Languages).

Indeed it was a sense of shaking off the shackles of traditional teaching, of moving into a quicker world unburdened by tradition, which made EFL in those days seem so exciting, especially from the point of young graduates in the UK who had themselves been taught by laborious traditional methods. It was 
this contrast which made the dynamic "craft" model evoke a sense of 1960 s liberation-coinciding as it did, for many of the trainees, with a personal liberation from school, parents and university, and the 1950s legacy of oppressive morality and conformity, and bringing with it opportunities for travel and independence through teaching EFL.

But like many of the apparent liberations of the 1960s, this one too, became for many - if not exactly illusory, yet certainly not as straightforward as it seemed at the time, and while liberating for privileged native English-speaking graduates, it was not necessarily so for their students or non-native-speaker colleagues. Even for the ascendant native speakers themselves there was a sense of superficiality and ephemerality both in the lives of individuals and of the EFL "profession" (if it merited that title) as a whole. This atmosphere of liberation followed by dissatisfaction ran on into the 1970s. Snapshot two: I was one such teacher myself. After only two weeks "teacher training" I arrived at a boys' secondary school in Upper Egypt in 1974 as a VSO (voluntary service overseas) teacher to discover that a local teacher had been moved out to make room for me, and that my colleagues regarded my presence as an imposition. I proceeded to flounder through a very formal exam syllabus, which involved explicit grammatical knowledge I did not have, and all my pupils did badly in their exams as a result.

It was such weaknesses which prompted and explains the widespread appeal of the next "phase"- though not a phase in the sense of something which replaced its predecessor-but one which ran alongside it. Wallace calls this "applied science" (with an implication of criticism), but I shall refer to it as "applied linguistics", because I want to make a distinction between the two, indeed to argue that they are polar opposites. Snapshot three: In 1977, in the first week of a PGCE at the London Institute of Education, I attended two very consciously contrasted lectures. One was by the outgoing head of EFL, Geoffrey Broughton, author of the bestselling Penguin Success with English course, the other by the incoming new Professor of Education for TESOL, Henry Widdowson. Broughton's lecture was a dazzling display of blackboard tricks and classroom tips - little pictures to convey different verb forms in English: "I am fishing", "I have been fishing", "I will go fishing", "I will have been fishing" etc. Henry Widdowson's lecture by contrast was a reflection on Russian linguist Roman Jakobson's six point taxonomy of language functions (Jakobson 1960). It was nothing directly to do with language teaching, but he deemed it nevertheless to have an indirect relevance, and thus to be appropriate to an audience of beginning teachers. 


\section{Applied linguistics}

The essence of applied linguistics for language teachers is a view of professionalism, education, and language teaching which is at odds not only with an exclusive focus on craft, but also with the current reductionist, utilitarian view of education (to which I shall return later) in which everything must be constantly audited for cost effectiveness.The idea-classically realised in masters degrees but also in elements of the longer teacher training courses-is to give teachers the time and the means to develop a deeper understanding of language and learning, not because it would quickly yield measurable results, nor because it is linked in any simple way to "being a good teacher" (it is a truism to observe that knowledge of applied linguistics does not have this effect) but because it would enrich teachers' own lives, give them a sense of professional integrity and independence, of knowing and understanding their vocation, which would lift them above the role of foot soldiers taking orders from on high (ministries, language schools, publishers etc.) and enable them to take command of their own activity.It was not just for the results it would yield for students and "clients" (as they were increasingly called), but for the teachers themselves, filling the vacuum that developed when the initial excitement of travel and classroom survival had died down.

Under these auspices MAs in applied linguistics have dealt not only with language teaching and learning but with such pedagogically "useless" linguistic topics as how infants acquire their first language, whether language is uniquely human, what is the point of education and, reflexively, what should teacher education involve. In short, "teacher training" became "teacher education" (Widdowson 1983: 19, 1990: 55-70). As time continues, the purview of applied linguistics continues to expand (Cook 2003), so that the list of "areas of current enquiry" on which the discipline's leading journal Applied Linguistics now welcomes contributions is a list of 17 , some of which (deaf linguistics, forensic linguistics, multimodal communication, lexicography, translation) are quite outside the scope of the early MA syllabuses. Such a disciplinary remit does not lend itself to short intensive training courses, nor to any notion of a quick return for one's money - whether this means the money of the individuals, employers, or the state. Applied linguistics presupposes an ethos where education is financed for its intrinsic value and with no strings attached (Brumfit 1995).

There is however a complication. As mentioned, I want to make a distinction between "applied linguistics" and Wallace's rather disparaging term "applied science". Under the auspices of applied linguistics there developed one area which did claim to be scientific and to yield on the back of its scientific findings a technology for language learning - in the same way that physics underpins engineering or chemistry underpins the pharmaceutical industry. This was Second Language Acquisition (SLA), which in its most simplistic 
manifestations, pinned its credentials on being able to improve teaching and learning, and thus, incidentally, implicitly justify expenditure on teacher education. When it did that, it brought applied linguistics into disrepute, firstly by talking about the very human activity of teaching in de-humanised terms ('input', 'output', 'monitors' etc.) and secondly by trampling over the accumulated wisdom of teachers, presuming to know better, and pushing aside as ill-informed the kind of classroom savvy, which the craft model had understood so well, and recommending on the back of its 'science' some "crazy" things (to use Chomsky's word again) — no use of the first language, no translation, no error correction no explanation of rules and so on and so forth. "Language teaching" as Scott Thornbury (2001) neatly put it "was at risk of being taken over by men in white coats". Though SLA has more recently redressed some of these excesses by taking a more social turn (Block 2003) and considering the extent of its pedagogic applicability (Ellis and Shintani 2013), there is still a good deal to redress.

It was in understandable reaction to such excesses of "applied science" and to the general academic nature of applied linguistics that the third of Wallace's models, reflective practice, acquired a growing following. My Snapshot 3 is this. In 2000 I was invited to speak at a conference in Cuba. I had by this time been an academic applied linguist myself for 15 years and I was confident that teachers wanted to hear what I had to tell them. The other speaker at the conference was the charismatic Dick Allwright, with whose work I was vaguely familiar. I was quite unprepared for the adulation with which his presence was hailed by teachers in Cuba, as it is in many parts of the world, for his work on "exploratory practice":

\footnotetext{
"a fully inclusive approach to practitioner research, with learners and teachers, as practitioners of learning and teaching, adopting the role of practitioner researchers as their normal way of using classroom time. Using standard classroom pedagogic practices they develop their own understandings of their learning and teaching lives." (Allwright 2012)
}

I realised to my chagrin that this approach to teaching and teacher education often strikes a chord with practising teachers in a way that applied linguistics does not.

Reflective practice and exploratory practice are about the experience of being a teacher, initiation into the teaching community, action research, personal development, teacher cognition, and beliefs - all of which are to be understood on the ground in context, by teachers themselves rather than by academics (like me), and within the practise of teaching rather than by withdrawing to gain perspective. To use Donald Freeman's metaphor, teaching is like shovelling snow in a snowstorm - charismatic you need to learn to do it on the ground- 
and museums of snow shovels, neatly displayed and labelled, will not help you. Under these auspices "teacher education" became "teacher development".

\section{Future directions}

Any programme for teacher education begins with a notion of what makes a good teacher, and what she or he needs to know and be. This must in turn draw upon a notion of what students need, want, and ought to know (not always the same). So the question arises - to what extent is the nature of English language teaching and learning the same as it was when the three models were formulated, and to what extent is it subject to the specifics of our time. In my remaining discussion, I shall consider some of these specifics, and propose five directions in which English language teacher education might take to accommodate them.

All of Wallace's three models remain relevant however. They are also complementary - rather than being mutually exclusive as their proponents sometimes claim. A good teacher needs classroom skills (craft), a deeper knowledge of their subject matter (applied linguistics), and also, while practising, to continually develop (reflective practice). Yet the three models, for all their complementary strengths, assume both a stable subject matter (the English language) and stable student needs (to acquire English for speaking and writing in monolingual English language environments). This assumption of stability allows the old models to focus inwards, advocating how teachers should orient towards the task of teaching, through classroom techniques, academic knowledge or introspection, rather than to focus outwards considering current instabilities in both the subject matter and student requirements and how they might impact on teachers. In this second section on future directions, I want to suggest that teacher education needs not another model of teacher training, education and development - we have adequate ones already - but a change of orientation, capable of preparing teachers for an unstable and rapidly changing environment. Contemporary teacher education needs primarily to cope with phenomena which, while they may not be entirely new to the world, have developed a scale and urgency which make English language learning in the contemporary world significantly different from the last decades of the last century.

\section{Technology}

Communication technology has changed and continues to do so at an accelerating rate in ways that affect both the needs and goals of Englishlanguage learners, and the relation between teachers and learners. The approaches to teaching and teacher education in the 60s-90s focussed primarily upon using English in face-to-face interaction or non-reciprocal reading and 
writing. Even when computer mediated communication became a central means of communication in everyday life, it continued to be relegated to a role in developing these skills. On-line communication should now no longer be only a means in English-language learning, but an end in itself as well. Digital communication has its own idiosyncratic English orthography, punctuation, grammar, vocabulary and conventions (Tagg forthcoming). These are, moreover, often better known by students, even at quite low levels, than by their older teachers, whether native or non-native. This in turn necessitates a difficult adjustment of traditional roles and relationships for which teachers need preparation.

Direction 1: Teacher education should focus on the communicative, linguistic and pedagogic consequences of constant rapid change in communication technology.

\section{The linguistic landscape}

In tandem, and equally dramatically, the linguistic landscape has changed and continues to change. In 1962 English was one of several international languages: French was the language of diplomacy; Russian the lingua franca of Eastern Europe and Central Asia; Russian and German a necessity for scientists; Portuguese and French were more important as post-colonial languages than they are now. In short English was not as extensive as it is today. The figures are imprecise and ever-changing. Much depends on how one defines a native speaker (Rampton 1990), second language speaker, or draws a line between English speaker and an English learner. Valiantly undeterred by the intractable nature of the problem, David Crystal continues to estimate the numbers. His 2012 estimate was 4-500 million native English speakers, 600 million second language speakers in countries where English is an official language, and another 500 million foreign language speakers, yielding a grand and growing total of 1.5 billion expert speakers of English. The figures do not include those still learning English, or with a partial knowledge of it (see also Seargeant 2012 and Schneider 2011).

This expansion has brought with it a fundamental change to the nature of learning English which cannot be ignored in teacher education. We can no longer assume that the prime aim of English language learners is only to communicate with native speakers on the ground in London, Sydney, or New York, or to fit obediently and unobtrusively into a North American, Australian or British "culture" (a major preoccupation of communicative language teaching). Learners are now as likely to be "speaking" English through a computer screen in Rio, Mumbai, or Shanghai with other non-native speakers, while those learners who do end up physically in an English-speaking country may do so as economic migrants or members of the world's privileged 
"transnational class", and will not necessarily want or need an "English identity". They live in a poly-lingual, poly-cultural world where people constantly shift and negotiate languages, where the world's English-speaking majority are other non-native speakers (Kramsch 2009).

Both for individuals and for whole nations this means that their relationship with English is quite different from what it was. It is no longer a language to move into temporarily. It is both an everyday language and an every day language - a second language for everyone, rather than a foreign language for anyone. When a language expands, as Widdowson (1994) has pointed out, its original speakers can no longer claim ownership, and their varieties become only as valid as other more recent ones. In contemporary applied linguistic theory this has given rise to the theorisation and description of English as a lingua franca (ELF) (Seidlhofer 2011; Cogo and Dewey 2012) and the realisation that nativespeaker models are no longer adequate in all contexts or for all purposes, and need to be included in teacher education (Seidlhofer 1999).

Direction 2: teacher education needs to prepare teachers to adjust to the state of the English language in the contemporary world, to be less prescriptive, and to accept and provide non-native models.

\section{Identity and the own language}

This in turn means that the world's new majority of non-native speakers of English experience ownership in two ways - one positive and one negative. Firstly they have a claim to "the ownership of English" themselves, but they also live with the danger of English taking ownership of them. The flow tends to be from English to other languages and from English-speaking cultures to nonEnglish-speaking cultures. In a report to UNESCO in 2010, for example, Heilbron estimated that of all the book translations in the world $55-60 \%$ are from English.

This should have implications for teaching and thus for teacher education. For in the new linguistic landscape the non-native expert users of English do not necessarily leave their own language behind them. They are as likely to be mediating between English and their own language, as using English monolingually. It is easy to overlook how, in actual real language use, as opposed to the supposed "real language" much trumpeted in EFL textbooks (sometimes based on native-speaker monolingual corpora). English frequently occurs not on its own, but alongside another language. Successful English language speakers often need to code-switch and translate, to operate bilingually rather than monolingually.

This constant movement back and forth between English and other languages is ubiquitous, from the most intimate and domestic situations, to the world stages of international affairs and media and everything in between. It 
happens in mixed-language marriages, in immigrant families, in visits by relatives and friends, in educational contexts, in workplaces, and, more formally, in interpreting and translation, news, diplomacy, bilingual or multilingual documents, packaging, announcements, food ingredients, flight information, subtitling and a host of other contexts.

This is an aspect of real English language use which has been inadequately addressed in EFL theory and practice, including teacher education. The assumption has always been that there is no need to relate English to the learner's own language, for example through explanation, discussion, or translation. This is misguided in many ways. It does not help learning, as it prevents new knowledge from being associated with existing knowledge. It denies the confidence and explicit knowledge which comes through explicit comparison with the student's own language (Cook 2010). It denies the inevitable - students compare the two languages anyway (Widdowson 2003). It damages good student teacher relations (Edstrom 2006, Brooks Lewis 2009). It also aggravates rather than redresses the unjust imbalance of languages in the world. For these and other reasons, there is now a growing literature advocating bilingual rather than monolingual English-language teaching (for a survey see Hall and Cook 2012).

Direction 3: EFL teachers need preparation to engage with their learners' own languages while teaching English, not only because this is needed and pedagogically efficient, but because it counterbalances the impoverishment of identity which comes when interlingual communication is one-way.

\section{Political allegiances: neoliberalism or civil society}

Wallace's three models are not overtly political, although the philosophical approaches to education behind them do imply certain broad political allegiances. In the terms of Allen (1983), a craft model implies a technological view of education, applied science an academic view, and reflective practice a humanistic approach (for alternative terminologies see Skilbeck 1982, Clark 1987). The current context of English language teaching is much more overtly political, however, and as with technological and linguistic landscape change, teacher education needs to reflect this. If teachers are to be treated as political pawns, they need to be prepared.

There is for example an ascendant current view of education peddled by businesses and governments which measures teaching and teacher education only in terms of value for money. Goals are expressed in terms of cost effectiveness for the funder, profits for the client, or higher earning potential for successful students. The aim of all education, including English language learning, is assumed to be the promotion of economic growth, as though growth were the solution to all of the world's ills, including environmental and social 
justice problems. In line with a neoliberal belief in market forces, cut-throat competition between nations, organisations and individuals is seen as desirable.

In this business model of teacher education, everything must be quantifiable, accountable, auditable, so that "impact" and "efficiency" can be measured, and "investment" compared with profit. This in turn leads management to prefer an obedient workforce, and this in turn has an effect on ideas of what a teacher is.

Teachers are no longer conceived as professionals with authority, independence and wisdom, but become mere "knowledge workers", a category characterised by my colleague Roxy Harris (2012) as employees

- engaged to 'deliver' packages of 'knowledge' generated by others

- highly controlled by management and regulation

- subservient to institutional goals

- penalised for independence of thought or ideas

- measured by student surveys and evaluations

- precariously employed

- limited or restricted in engagement with research and publication

This model of the teacher is a neoliberal phenomenon which has politicised English Language Teaching (Block et al. 2012), and education more generally (Collini 2011, 2012) and promoted an agenda which is quite alien to the valuable ideal of the teacher as an authoritative, disinterested, independent professional. This poses a danger to teacher education and to teaching professionalism more generally, and all three models of teacher education need to take account of it if they are not to be overwhelmed. For not only is the neoliberal cult incompatible with the applied linguistics and reflective models of teacher education - both of which necessitate substantial use of time which is not immediately profitable, it is also (but less obviously) incompatible with the spirit of the early "craft" model of EFL teacher training, which was not entirely motivated by business concerns. In the 1960s the idea of a craft approach was, in the energetic and iconoclastic mood of the times, to provide a quick and effective passing on of practical skills to would-be EFL teachers, without all the cumbersome apparatus of tradition. But it would be wrong to confuse this concentration on effectiveness with the current obsession with efficiency and value for money in education. The same phenomena can have quite different values and meanings in different contexts and at different points in history.

Direction 4: teachers should be educated in a way which helps them critique and resist a neoliberal business model of language teaching. 


\section{Civil society}

In many ways directly contrary to the competitive neoliberal interference in education is the view that English language teaching can contribute to the growth of a global civil society (Birch 2009), conceived as a "process through which groups, movements and individuals" working independently of governments, religions and businesses "can [civilize or democratize globalization] and demand a global rule of law, global justice, and global empowerment" (Kaldor 2003: 12). A global language like any form of knowledge is morally neutral and can be used for good or bad. So as well as, or instead of, being used for financial gain, and the promotion of national or individual interests, it can also be used in an internationalist spirit in environmental protection, in climate change stabilisation, in conflict resolution, in disarmament negotiations, to promote labour rights and fair trade, and by transnational organisations such as Amnesty, The Red Cross, Greenpeace, Human Rights Watch, Global Reporting Initiative, Wikimedia, Médicins Sans Frontières (which despite its name operates in English) and many others-even paradoxically in the campaigns for the preservation of endangered languages and cultures. English language teachers education could develop and discuss these goals.

Direction 5: EFL teacher education could embrace and promote the ideal of a global civil society.

\section{Conclusion}

Past models of teacher education are still relevant and important, but they do not adequately address aspects of contemporary English language use and learning. In these notes I have tried to suggest some directions to be added as major components of English language teacher education in the future.

\section{Works cited}

Allen, J. P. B. 1983. 'General Purpose Language Teaching: a variable focus approach'. In Brumfit, C.J.(ed.) General English Syllabus Design. Oxford: Pergamon 6174.

Allwright Dick 2012. IATEFL Research SIG event 'Exploratory Practice' Leicester, UK, 7 July 2012.

Anthony, Edward M. 1963. “Approach, method and technique.”English Language Teaching 17: 63-57

Birch, Barbara 2009. The English Language Teacher and Global Civil Society.London: Routledge.

Block, D. 2003. The Social Turn in Second Language Acquisition.Edinburgh: Edinburgh University Press. 
Block, David, John Grey and MarnieHolborow. 2012. Neoliberalism and Applied Linguistics, Routledge.

Brooks-Lewis, K. A. 2009. Adult Learners' Perceptions of the Incorporation of their L1 in Foreign Language Teaching and Learning.Applied Linguistics, 30/2: 216235.

Brumfit, C. J. 1995. Teacher professionalism and research. In Guy Cook and Barbara Seidlhofer (eds.). Principle and practice in applied linguistics. Oxford:Oxford UP: 27-42.

Chomsky, Noam 1965. Aspects of the Theory of Syntax, Cambridge, Mass.: MIT.

Chomsky, Noam. 1988. Language and the problems of knowledge: The Managua lectures. MIT Press.

Clark, John. 1987. Curriculum Renewal in School Foreign Language Learning. Oxford: Oxford University Press

Cogo, Alessia.and Martin Dewey 2012. Analysing English as a Lingua Franca: A corpus- based investigation.London: Continuum.

Collini, Stefan 2012. What are universities for? London: Penguin.

Collini, Stefan. 2011. From Robbins to McKinsey. London Review of Books 33/16:9-14.

Cook, Guy 2003. Applied Linguistics. (In the series Oxford Introductions to Language Study) Oxford: Oxford University Press.

Cook, Guy 2010. Translation in Language Teaching: an argument for reassessment. Oxford University Press.

Crystal, David 2012. A global language. In P. Seargeant and J. Swann (eds) English in the world: history, diversity, change. Abingdon: Routledge.

Edstrom, A. (2006). L1 Use in the L2 Classroom: One Teacher's Self-Evaluation. The Canadian Modern Language Review, 3/2: 275-292.

Ellis, Rod and NatsukoShintani.2013 Exploring Language Pedagogy through Second Language Acquisition Research. London: Routledge.

Freeman, Donald. 1996. 'Redefining the relationship between research and what teachers should know' in K.M. Bailey and D. Nunan (eds.), Voices from the Language Classroom. Cambridge: Cambridge University Press. 88-115.

Hall, Graham and Guy Cook (2012) 'Own language use in language teaching and learning: the state of the art.' Language teaching 45/3: 271-308.

Harris, Roxy 2012.Intellectuals, Academics, or Knowledge Workers Unpublished seminar paper, King's College London.

Haycraft, John 1998. Adventures of a Language Traveller.London: Constable.

Heilbron, JohanStructure and Dynamics of the World System of Translation UNESCO, International Symposium 'Translation and Cultural Mediation', February 22-23, 2010. Available on-line http://portal.unesco.org/culture/en/files/40619/12684038723Heilbron.pdf/Heilbr on.pdf

Howatt, A. P. R. with H.G.Widdowson. 2004. A History of English Language Teaching. (second edition) Oxford: Oxford University Press.

Jakobson, R. 1960. 'Closing statement: linguistics and poetics' in T.A. Sebeok (ed.)Style in Language. Cambridge, Massachusetts: MIT Press.

Kaldor, M. 2003. Global Civil Society: An End to War. Cambridge: Polity Press.

Kramsch, Claire 2009. The Multilingual Subject Oxford University Press. 
Rampton, Ben. 1990. "Displacing the 'native speaker': Expertise, affiliation and inheritance." ELT Journal44(2).

Schneider, E. W. 2011. English around the world: an introduction. Cambridge: Cambridge University Press.

Seargeant, Philip. 2012. Exploring World Englishes: language in a global context. London: Routledge.

Seidlhofer, Barbara 1999. "Double standards: Teacher education in the expanding circle." World Englishes 18/2: 233-245.

Seidlhofer, Barbara 2011. Understanding English as a lingua franca. Oxford, Oxford University Press.

Skilbeck, M. 1982. 'Three Educational ideologies' in T.Horton and Raggat (eds.) Challenge and Change in the Curriculum. Sevenoaks: Hodder and Stoughton.

Tagg, Caroline. Forthcoming 2014.Exploring Digital Communication. London: Routledge.

Thornbury, Scott 2001 Lighten up. A reply to Angeles Clemente. ELT Journal 55/4

Wallace, Michael 1991. Training Foreign Language Teachers: a reflective approach. Cambridge: Cambridge University Press.

Widdowson, H. G. 1983 Learning Purpose and Language Use. Oxford: Oxford University Press.

Widdowson, H. G. 1984. 'Models and Fictions' in Explorations in Applied Linguistics 2: 7-21. Oxford: Oxford University Press.

Widdowson, H. G. 1990. 'Pedagogic research and teacher education'. In Aspects of Language Teaching, Oxford: Oxford University Press.

Widdowson, H. G. 1994. The Ownership of English.' TESOL Quarterly 28:377-389.

Widdowson, H. G. 2003. Defining Issues in English Language Teaching. Oxford:

Oxford University Press 